\section{Acute chest pain and massive LV hypertrophy in a 38-year-old} man

\section{CASE-PART I}

A previously healthy 38-year-old man with no history of cardiovascular disease presented with symptoms of upper respiratory tract infection, acute chest pain, inferior ST-elevation on ECG and a troponin $\mathrm{I}>60 \mu \mathrm{g} / \mathrm{L}$ (normal $<0.04 \mu \mathrm{g} / \mathrm{L}$ ). Emergency coronary angiography demonstrated normal coronary arteries. Echocardiogram showed moderate impairment of LV systolic function, inferoposterior wall hypokinesis and severe concentric LV hypertrophy (septum up to $22 \mathrm{~mm}$ ) with a speckled appearance. A cardiovascular MR (CMR) study was requested to further evaluate the cause of LV hypertrophy (figure 1).

Based on these CMR images (and online supplementary video), the most likely diagnosis is:

A. Hypertrophic cardiomyopathy (HCM)

B. Acute myocarditis

C. Cardiac amyloidosis
D. Anderson-Fabry disease

E. Athlete's heart

\section{CASE-PART II}

CMR showed mild global LV hypokinesis (EF 62\%) and severe concentric hypertrophy (wall thickness $20 \mathrm{~mm}$, LV mass $250 \mathrm{~g}$ ). On T2-weighted imaging, there was a significant increase in global myocardial signal intensity (SI) when compared with adjacent skeletal muscle (T2 SI ratio 2.8; normal <2.0), demonstrating global myocardial oedema. On T1-maps, ${ }^{1}$ green areas denote normal myocardium (normal T1 value $962 \pm 25 \mathrm{~ms}$ at $1.5 \mathrm{Tesla}$ ), ${ }^{2}$ whereas red indicates areas of myocardium with a significant increase in T1 value of $>990 \mathrm{~ms}$, consistent with acute myocardial oedema. ${ }^{3}$ In this patient, there was a significant $(\sim 10 \%)$ increase in mean myocardial T1 (1054 $\pm 62 \mathrm{~ms})$. Late gadolinium enhancement (LGE) imaging showed a predominantly non-ischemic pattern of myocyte necrosis, with diffuse hazy enhancement throughout the $\mathrm{LV}$ and areas of subepicardial and mid-wall enhancement in a noncoronary distribution, consistent with myocarditis. This is in contrast to acute myocardial infarction, which typically shows an area of LGE with subendocardial involvement and variable transmural extent in the distribution of a single coronary artery.

For answers see page 351

Heart 2014;100:347. doi:10.1136/heartjnl-2013-305021

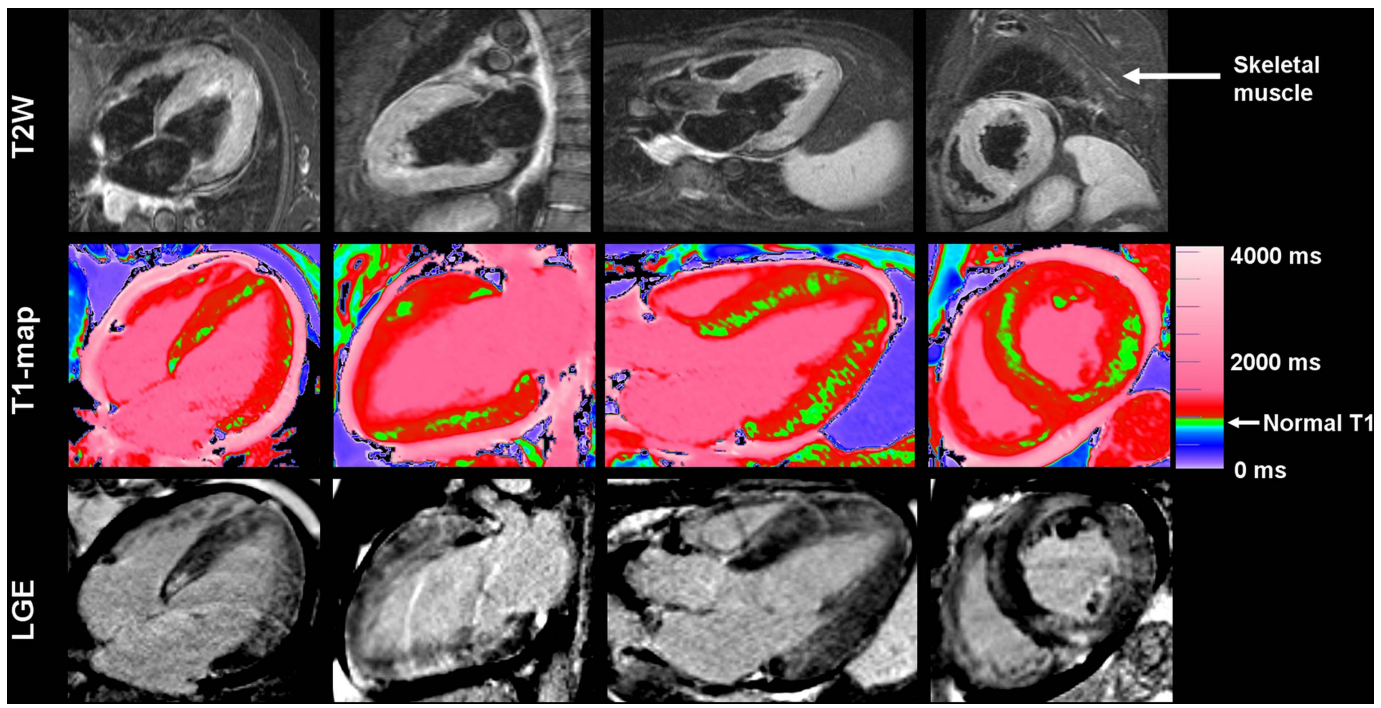

Figure 1 Conventional field strength cardiovascular MR at 1.5 Tesla using tissue characterisation techniques. (From left to right) 4-chamber, 2-chamber, 3-chamber and mid-ventricular short-axis views. T2-weighted (T2W) images detect myocardial oedema when the ratio of myocardial T2 signal intensity compared with skeletal muscle is $>2.0$; T1-maps display areas of normal left ventricular myocardium (green; normal T1=962 \pm 25 ms) and areas with abnormal T1 values by the use of colour scales (red indicates areas with significantly increased T1 >990 ms consistent with oedema). On late gadolinium enhancement (LGE) images, normal myocardium is nulled to black, whereas areas of abnormality (whether myocyte necrosis, scar or expanded interstitial space) appear white. 
IMAGE CHALLENGE

\section{Acute chest pain and massive LV hypertrophy in a 38-year-old man}

\author{
ANSWER \\ From question on page 347
}

The correct answer is (B). Extensive acute myocarditis was most likely, with severe oedema causing a significant increase in wall thickness and mass. However, given the severe LV hypertrophy (20 mm), background HCM with concomitant myocarditis was a possibility. A follow-up CMR was important in this case which showed resolution of the oedema (global myocardial T2 SI ratio $1.5)$, with normalisation of the LV mass (102 g), wall thickness $(8-12 \mathrm{~mm})$ and mean myocardial T1 $(964 \pm 72 \mathrm{~ms})$. There was also significant reduction in the areas of LGE. Normalisation of the massive changes at presentation in follow-up allowed exclusion of HCM and amyloidosis. Cardiac amyloidosis was also less likely as atrial sizes were normal without LGE, and LGE images typically show diffuse, mostly subendocardial enhancement in the LV with dark blood pool (due to binding of the gadolinium contrast to the amyloid protein); cardiac amyloidosis also shows a much higher increase $(\sim 19 \%)$ in mean myocardial T1 $(1140 \pm 61 \mathrm{~ms}) .{ }^{4}$ Anderson-Fabry disease is a lysosomal storage disease due to $\mathrm{X}$ linked recessive deficiency of the enzyme $\alpha$-galactosidase, which leads to accumulation of glycosphingolipid within lysosomes. It typically shows moderate-to-severe concentric hypertrophy, mid-wall LGE in the basal inferolateral wall and low myocardial T1 values (882 $\pm 47 \mathrm{~ms}) .^{5}$ Athlete's heart does not present with features of oedema, and the degree of physiologic hypertrophy is mild (13$15 \mathrm{~mm}$ in wall thickness), which normalises with detraining.

\section{Vanessa M Ferreira, ${ }^{1}$ Stefan K Piechnik, ${ }^{1}$ Soroosh Firoozan, ${ }^{2}$ Theodoros D Karamitsos, ${ }^{1}$ Stefan Neubauer ${ }^{1}$ \\ ${ }^{1}$ Division of Cardiovascular Medicine, Raddliffe Department of Medicine, University of Oxford, John Radcliffe Hospital, Oxford, UK \\ ${ }^{2}$ Department of Cardiology, Wycombe Hospital, High Wycombe, UK}

Correspondence to Dr Vanessa Ferreira, Division of Cardiovascular Medicine, Radcliffe Department of Medicine, University of Oxford, John Radcliffe Hospital, Oxford, UK; vanessa.ferreira@cardiov.ox.ac.uk

- Additional material is published online only. To view please visit the journal online (http://dx.doi.org/10.1136/heartjnl-2013-305021).

Contributors All authors gave final approval of the version published. Additionally, VMF was involved in the conception of the manuscript, acquisition of the images, analysis and interpretaion of data and drafting the article; SKP was involved in data analysis, design of the threshold-based colour scale for coloured T1-maps and revision of the article and SF was involved in the conception and revision of the article. TDK and SN were involved in the conception of the article, interpretation of data and revision of the article for important intellectual content.

Competing interests VMF and SKP are funded by the Oxford National Institute for Health Research Biomedical Research Centre Programme. VMF received funding from the Alberta Innovates Health Solutions Clinical Fellowship and the University of Oxford Clarendon Fund Scholarship. SN acknowledges support from the British Heart Foundation Centre of Research Excellence, Oxford. The authors acknowledge support by the Oxford National Institute for Health Research Biomedical Research Centre Programme. Dr. Piechnik has a patent Sh-MOLLI cardiac gated T1 mapping of T1 licensed to Siemens, and a patent colour map design method for immediate assessment of the deviation from established normal population statistics and its application to cardiovascular T1 mapping images pending.

Patient consent Obtained.

Provenance and peer review Not commissioned; internally peer reviewed.
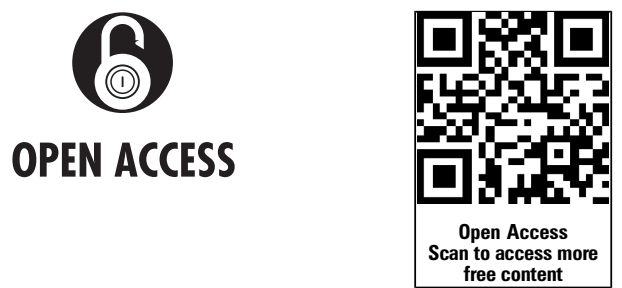

Open Access This is an Open Access article distributed in accordance with the Creative Commons Attribution Non Commercial (CC BY-NC 3.0) license, which permits others to distribute, remix, adapt, build upon this work non-commercially, and license their derivative works on different terms, provided the original work is properly cited and the use is non-commercial. See: http://creativecommons.org/ licenses/by-nc/3.0/

To cite Ferreira VM, Piechnik SK, Firoozan S, et al. Heart 2014;100:351.

Received 9 October 2013

Accepted 30 October 2013

Published Online First 29 November 2013

Heart 2014;100:351. doi:10.1136/heartjnl-2013-305021a

\section{REFERENCES}

1 Piechnik SK, Ferreira VM, Dall'Armellina E, et al. Shortened Modified Look-Locker Inversion recovery (ShMOLLI) for clinical myocardial T1-mapping at 1.5 and $3 \mathrm{~T}$ within a 9 heartbeat breathhold. I Cardiovasc Magn Reson 2010;12:69.

2 Piechnik S, Ferreira V, Lewandowski $A$, et al. Normal variation of magnetic resonance T1 relaxation times in the human population at 1.5 T using ShMOLLI. J Cardiovasc Magn Reson 2013:15:13.

3 Ferreira V, Piechnik S, Dall'Armellina E, et al. Non-contrast T1-mapping detects acute myocardial edema with high diagnostic accuracy: a comparison to T2-weighted cardiovascular magnetic resonance. J Cardiovasc Magn Reson 2012;14:42.

4 Karamitsos TD, Piechnik SK, Banypersad S, et al. Non-contrast T1 mapping for the diagnosis of cardiac amyloidosis. JACC Cardiovasc Imaging 2013;6:488-97.

5 Sado DM, White SK, Piechnik SK, et al. Identification and assessment of Anderson-Fabry disease by cardiovascular magnetic resonance noncontrast myocardial T1 mapping. Circulation Cardiovasc Imaging 2013;6:392-8. 